Check for updates

Cite this: RSC Adv., 2017, 7, 53570

\title{
Acetylcholinesterase biosensor based on electrochemically inducing 3D graphene oxide network/multi-walled carbon nanotube composites for detection of pesticides $\uparrow$
}

\begin{abstract}
Yanping Li, Ruixia Zhao, Lingyun Shi, Gaoyi Han (D)* and Yaoming Xiao
A sensitive electrochemical biosensor for determining organophosphates (OPs) and carbamate pesticides has been achieved by immobilizing acetylcholinesterase (AChE) on electrochemically inducing 3D graphene oxide network/multi-walled carbon nanotube composites (e-GON-MWCNTs). The nanocomposites of e-GON-MWCNTs can provide a favorable environment for the immobilized AChE and improve the electron transfer speed between the analyte and electrode surface. The fabricated AChE biosensors show a favorable affinity to acetylthiocholine chloride (ATCl) with a Michaelis-Menten constant of $0.43 \mathrm{mmol} \mathrm{L}^{-1}$. In the optimal conditions, the biosensor exhibits a linear range of $0.03-0.81$ $\mathrm{ng} \mathrm{mL^{-1 }}$ for detecting carbofuran, and two linear ranges of $0.05-1 \mathrm{ng} \mathrm{mL}^{-1}$ and $1-104 \mathrm{ng} \mathrm{mL}^{-1}$ for detecting paraoxon. Furthermore, the detection limits for carbofuran and paraoxon can reach 0.015 and $0.025 \mathrm{ng} \mathrm{mL} \mathrm{m}^{-1}$, respectively. The AChE biosensor exhibits good reproducibility and high stability, which demonstrates good efficiency in real sample analysis.
\end{abstract}

Received 26th July 2017

Accepted 8th November 2017

DOI: $10.1039 / \mathrm{c} 7 \mathrm{ra0} 8226 \mathrm{f}$

rsc.li/rsc-advances strength. ${ }^{22-24}$ However, CNTs are inclined to form bundles and graphene sheets are easy to stack together because of the strong van der Waals interactions, suppressing their intrinsically unique properties. ${ }^{25}$ Therefore the method for preparing graphene-CNTs nanohybrids has been developed by using them as spacers for each other to prevent graphene stacking and CNTs bundling and form a three-dimensional (3D) architecture. ${ }^{26,27}$ The reported preparation methods mainly include hydrothermal ${ }^{26,27}$ and chemical vapor deposition method..$^{28}$

The formed 3D nanostructures not only inherit the virtues of CNTs and graphene, but also provide extraordinary physicochemical, mechanical and electrical properties. ${ }^{28-33}$ For instance, the composite of multi-walled carbon nanotubes (MWCNTs) and graphene oxide (GO) has been used to construct sensing interface for simultaneous measurement of sunset tartrazine and Yellow by Lu's group, it is found that the electrodes show an enhanced electrochemical response due to the synergistic catalysis of GO and CNTs. ${ }^{32}$ Wang et al. have fabricated an effective electrochemical biosensor for carbaryl determination by covalently immobilizing acetylcholinesterase on MWCNTs/GO nanoribbons. ${ }^{31}$ Compared with traditional planar electrodes, the reported electrochemical sensors based on 3D graphene-CNT hybrid may offer higher sensitivity or larger detection range, ${ }^{28}$ which has simulated many attentions due to their great potential in fabricating high-quality electrochemical sensors.

Biocompatible GO sheets as a sensor platform not only provide plentiful binding sites for AChE, but also play a role of
The Institute of Molecular Science, Key Laboratory of Materials for Energy Conversion and Storage of Shanxi Province, Shanxi University, Taiyuan, China 030006. E-mail: han_gaoyis@sxu.edu.cn; Fax: +86-351-7016358; Tel: +86-351-7010699

$\dagger$ Electronic supplementary information (ESI) available. See DOI: 10.1039/c7ra08226f 
signal amplification in electrochemical detection. ${ }^{31,32}$ Nevertheless, the application of pure GO-modified GCE in the detection of paraoxon and carbofuran has been limited by its insulating property. On the other hand, MWCNTs can improve the electrical conductivity and the stability of the composite on the modified glassy carbon electrode (GCE).

Here, a simple and green approach has been developed to prepare electrochemically inducing 3D graphene oxide network/ MWCNTs composites (e-GON/MWCNTs) using cyclic voltammetry (CV) method. Then the AChE is immobilized on the nanostructure of e-GON/MWCNTs to fabricate the electrochemical sensor for the carbofuran and paraoxon testing. In the optimum conditions, the biosensor has showed high sensitivity, long-term stability and good reproducibility which mainly come from the synergistic effects of unique properties of graphene and MWCNTs.

\section{Experimental}

\subsection{Reagents}

AChE (type C3389 and $500 \mathrm{U} \mathrm{mg}^{-1}$ from electric eel), ATCl, carbofuran and paraoxon were procured from Sigma-Aldrich. MWCNTs were bought from Chengdu Institute of Organic Chemistry. Phosphate buffer solution (PBS, $0.1 \mathrm{~mol} \mathrm{~L}^{-1}$, $\mathrm{pH} 7.4$ ) was prepared from $\mathrm{NaH}_{2} \mathrm{PO}_{4}$ and $\mathrm{Na}_{2} \mathrm{HPO}_{4}$. Other reagents were of analytical grade. Aqueous solutions were prepared with double distilled (DI) water.

\subsection{Instruments}

Electrochemical measurements were done using CHI $760 \mathrm{E}$ workstation (Shanghai Chenhua Instruments, China). A threeelectrode cell was used with the unmodified or modified glass carbon electrode (GCE) as the working electrodes, a saturated calomel electrode (SCE) and a platinum plate served as the reference electrode and the auxiliary electrode, respectively. Surface morphology of samples was investigated using a scanning electron microscope (SEM) (JEOL-JSM-6701F) and a transmission electron microscope (TEM, JEOL-JEM-1011). Nitrogen adsorption-desorption isotherms were performed on a Micromeritics ASAP2460 volumetric adsorption system at $77 \mathrm{~K}$.

\subsection{Preparation of AChE biosensors}

GO was synthesized by the modified Hummers method. ${ }^{34}$ The homogeneous GO/MWCNTs colloidal suspension with mass ratio of $3: 1$ was prepared by ultra sonicating of GO and MWCNTs in DI water.

Before modification, GCE was polished with $0.3 \mu \mathrm{m}$ and 0.05 $\mu \mathrm{m} \mathrm{Al}_{2} \mathrm{O}_{3}$ slurry carefully and then sequentially sonicated for $3 \mathrm{~min}$ in $1: 1$ aqueous $\mathrm{HNO}_{3}(\mathrm{~V} / \mathrm{V})$, absolute alcohol and DI water, respectively. After being rinsed with DI water and dried under ambient conditions, as displayed in Scheme 1, $6 \mu \mathrm{L}$ $0.04 \mathrm{mg} \mathrm{mL}^{-1} \mathrm{GO}-\mathrm{MWCNTs}$ aqueous dispersion was dropped upon the GCE and dried in air (labeled as GO-MWCNTs/GCE). Then, the GO-MWCNTs/GCE was electrochemically activated in $0.5 \mathrm{~mol} \mathrm{~L}^{-1} \mathrm{H}_{2} \mathrm{SO}_{4}$ by successive $\mathrm{CV}$ scanning between -0.6 and $1.0 \mathrm{~V}$ (scan rate of $50 \mathrm{mV} \mathrm{s}^{-1}$ ) for 17 cycles to obtain e-GONMWCNTs/GCE. After being carefully rinsed with DI water and dried under ambient conditions, $5 \mu \mathrm{L}$ AChE was loaded on the e-GON-MWCNTs/GCE. Finally, the obtained AChE/e-GONMWCNTs/GCE was stored at $4{ }^{\circ} \mathrm{C}$ when not in use. For comparison, AChE-GO-MWCNTs/GCE was fabricated in the similar way without electrochemical activation.

\subsection{Measurement procedure}

For the measurements of carbofuran and paraoxon, the initial differential pulse voltammetry (DPV) response was first recorded in PBS (pH 7.4) containing $7.5 \mathrm{mmol} \mathrm{L}^{-1}$ ATCl. Next, the proposed electrode was immersed in desired concentrations of

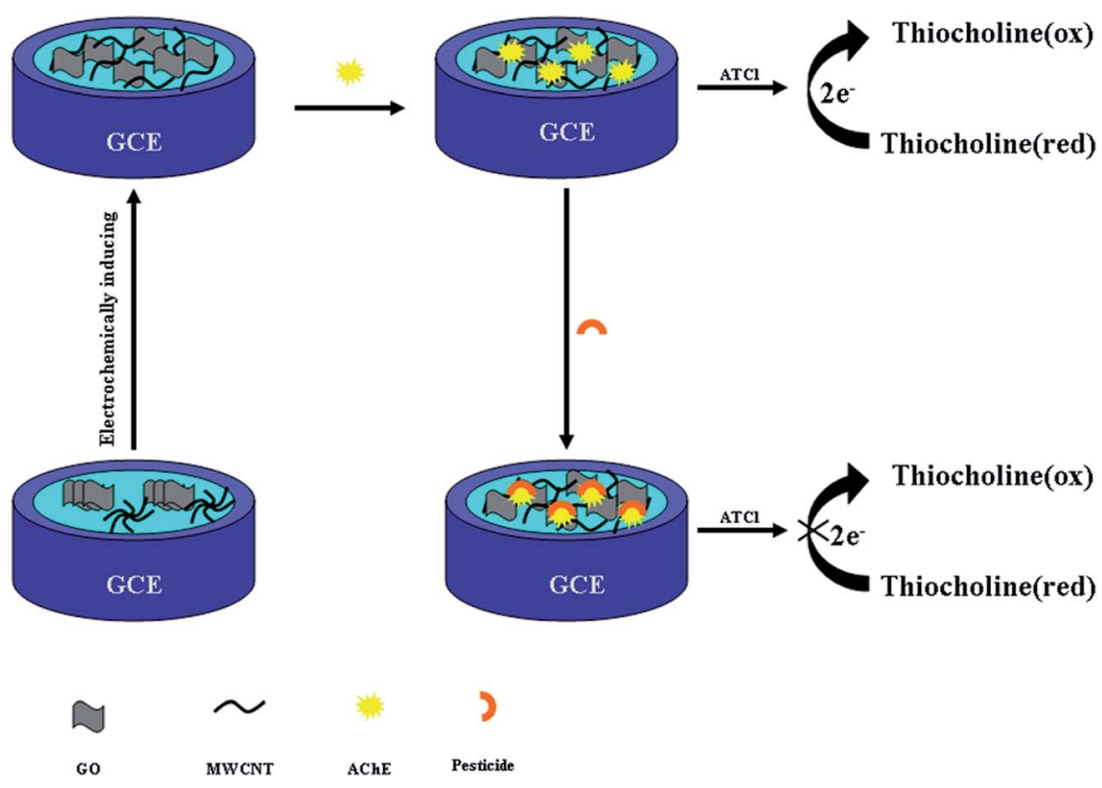

Scheme 1 Schematic diagram of the fabrication and principle of the electrochemical AChE biosensor. 
standard carbofuran and paraoxon for $10 \mathrm{~min}$ and then transferred into PBS containing $7.5 \mathrm{mmol} \mathrm{L}^{-1}$ ATCl for DPV measurements. The inhibition rate $(I \%)$ of pesticides was calculated using the following formula:

$$
I \%=\frac{i_{\mathrm{p}, \text { control }}-i_{\mathrm{p}, \mathrm{exp}}}{i_{\mathrm{p}, \text { control }}} \times 100 \%
$$
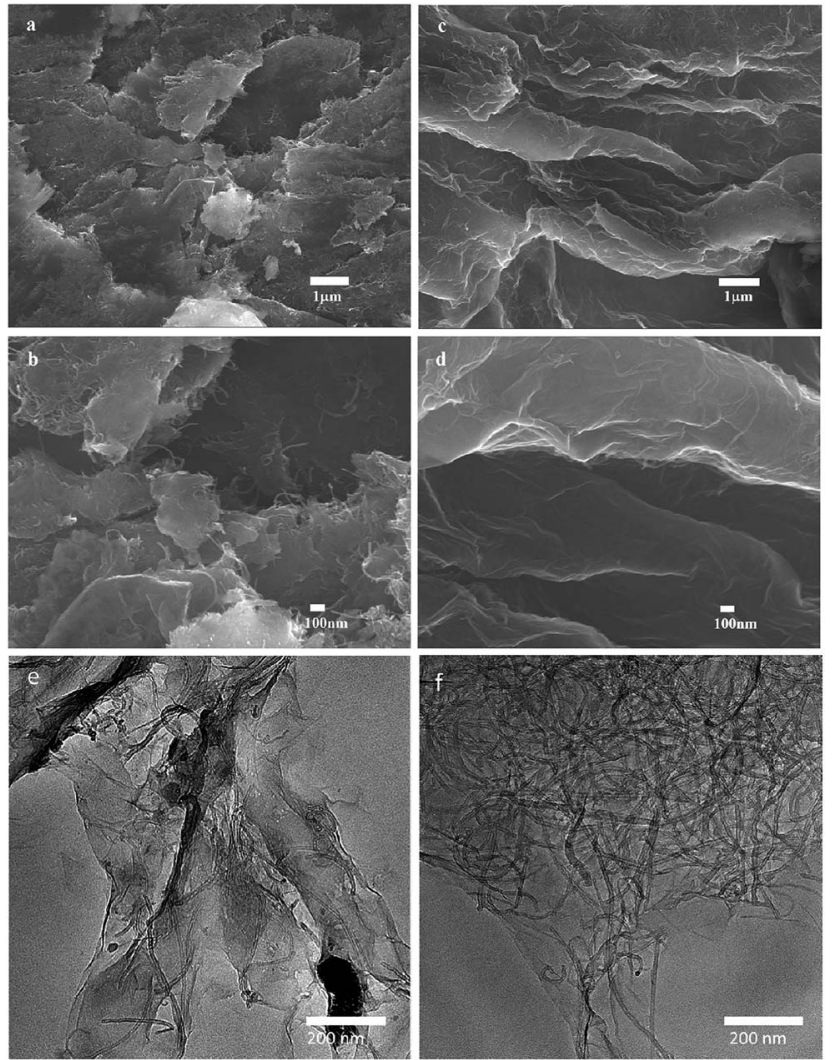

Fig. 1 SEM images of (a, b) GO-MWCNTs and (c, d) e-GONMWCNTs, ( $a$ and $c$ ) images are in low magnification, ( $b$ and $d$ ) images are in high magnification. TEM images of (e) GO-MWCNTs and (f) eGON-MWCNTs. where $i_{\mathrm{p} \text {,control }}$ and $i_{\mathrm{p} \text {,exp }}$ were the biosensor response without and with pesticides inhibition, respectively.

\section{Results and discussion}

\subsection{Characterization of e-GON-MWCNTs}

As shown in Fig. 1, the surface morphology of GO-MWCNTs shows a compact structure (Fig. 1a and b), the sheets in GOMWCNTs stack owing to intersheet van der Waals interactions, resulting in the loss of effective electrolyte-accessible surface area. However, the e-GON-MWCNTs shows a coarse and aligned structure, the partially peeling GO-MWCNTs each other form the 3D conductive network (Fig. 1c and d) because of the fast diffusion of electrolyte or the release of minute amounts of gas during the successive CV process. It can be also clearly seen that the GO-MWCNTs stack together due to the strong $\pi-\pi$ interactions (Fig. 1e). Nevertheless, e-GON-MWCNTs reveal that the well dispersed MWCNTs are adhered well to the GO sheets (Fig. 1f).

Fig. 2 depicts the nitrogen adsorption/desorption isotherm curves of e-GON-MWCNTs and GO-MWCNTs along with their pore size distributions. The BET surface area and pore volume data are given in Table 1. It is noted that the e-GON-MWCNTs have greater specific surface area and pore volume than GOMWCNTs, which can be also attributed to the rapid diffusion of electrolyte or the microscale of gas release during the successive $\mathrm{CV}$ process which partially peel GO-MWCNTs each other to form the 3D network e-GON-MWCNTs.

\subsection{EIS measurement}

EIS is an efficient method for probing interfacial properties of surface-modified electrodes. ${ }^{35}$ Fig. 3 shows the EIS of bare GCE, GO-MWCNTs/GCE, e-GON-MWCNTs/GCE and AChE/e-GONMWCNTs/GCE. The impedance spectrum corresponding to each step is fitted by using Zview to obtain the equivalent circuit (bottom inset in Fig. 3). From the fitting values listed in Table $\mathrm{S} 1, \dagger$ it is found that the GO-MWCNTs/GCE $\left(59.21 \Omega \mathrm{cm}^{2}\right)$
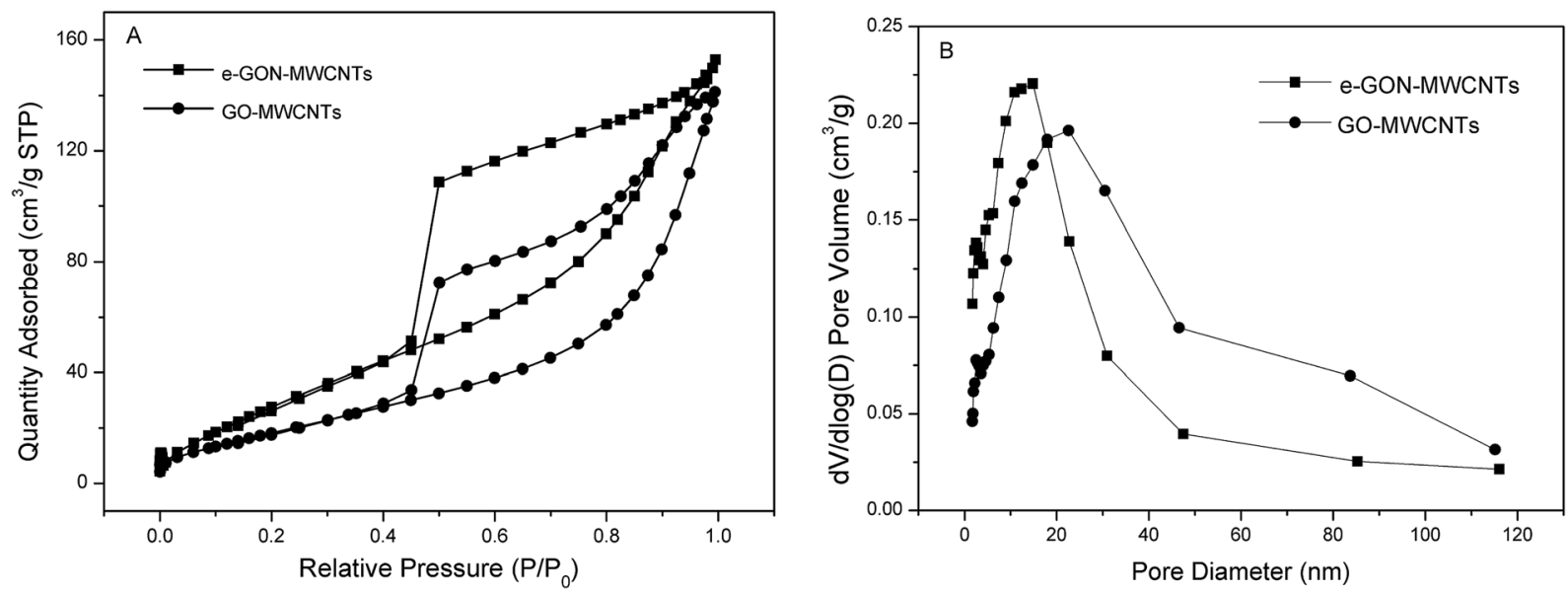

Fig. 2 (A) Nitrogen adsorption/desorption isotherm curves of e-GON-MWCNTs and GO-MWCNTs. (B) Pore size distributions derived from isothermal adsorption plots. 
Table 1 Specific surface areas and pore volume of e-GON-MWCNTs and GO-MWCNTs

\begin{tabular}{lcl}
\hline & $\begin{array}{l}\text { BET surface } \\
\text { area }\left(\mathrm{m}^{2} \mathrm{~g}^{-1}\right)\end{array}$ & $\begin{array}{l}\text { Pore volume } \\
\left(\mathrm{cm}^{3} \mathrm{~g}^{-1}\right)\end{array}$ \\
\hline GO-MWCNTs & 76.9 & 0.21 \\
e-GON-MWCNTs & 130.6 & 0.23 \\
\hline
\end{tabular}

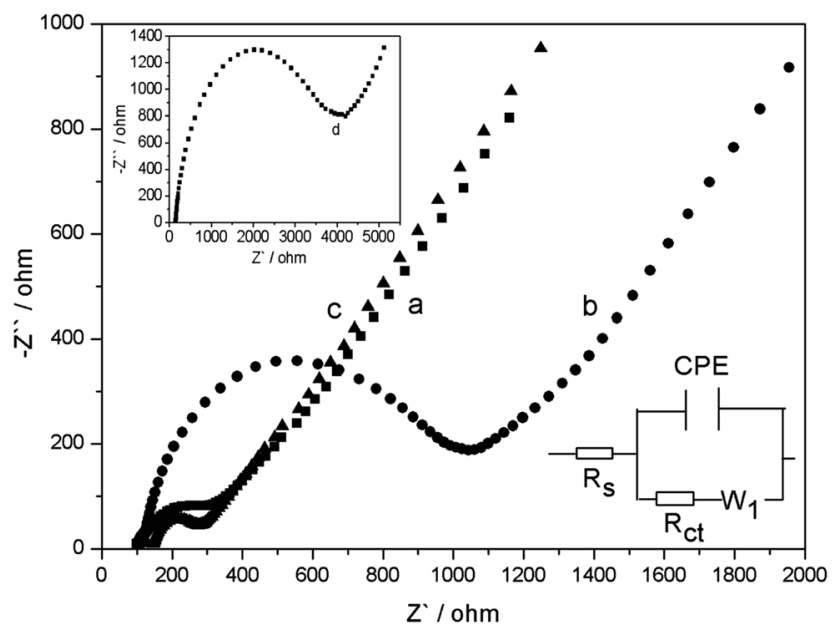

Fig. 3 EIS spectra of bare GCE (a), GO-MWCNTs/GCE (b) and eGON-MWCNTs/GCE (c) in $5.0 \mathrm{mmol} \mathrm{L}^{-1} \mathrm{Fe}(\mathrm{CN})_{6}{ }^{4-13-}$. Top inset: Nyquist plots of AChE/e-GON-MWCNTs/GCE (d). Bottom inset: equivalent circuit.

exhibits a higher $R_{\mathrm{ct}}$ value than bare GCE $\left(15.44 \Omega \mathrm{cm}^{2}\right)$, indicating that GO in GO-MWCNTs acts as an insulating layer which reduces electron-transfer rate. However, the $R_{\mathrm{ct}}(8.29 \Omega$ $\mathrm{cm}^{2}$ ) of e-GON-MWCNTs electrode is dramatically declined, indicating the excellent electron shuttling property of e-GONMWCNTs. The 3D conductive network makes it more feasible for the electrochemical detection of the products from enzymatic reactions. It is notable that the interfacial resistance

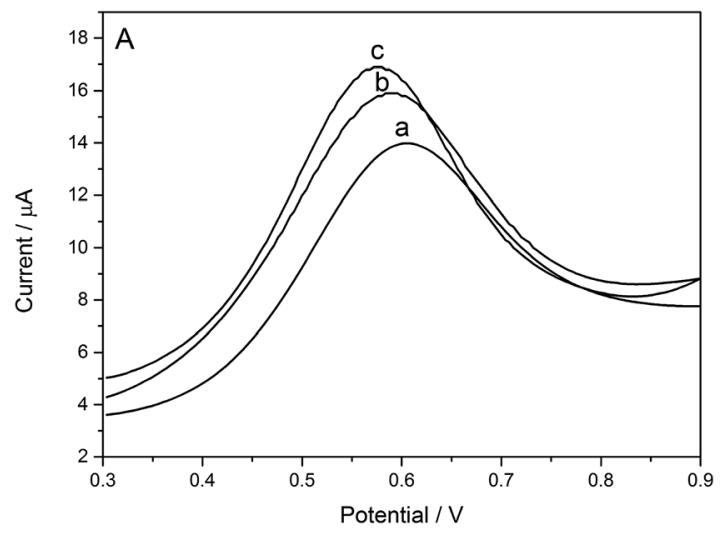

increases to $168.34 \Omega \mathrm{cm}^{2}$ after the immobilization of AChE on e-GON-MWCNTs/GCE electrode surface. This phenomenon is attributed to the macro-biomolecule blocking the interfacial electron transfer, which is also the direct evidence of successful binding of enzyme on the electrode surface.

\subsection{Electrochemical behavior of AChE/e-GON-MWCNTs/ GCE}

The DPV responses of ATCl on the bare and modified electrodes are shown in Fig. 4A. Obvious oxidation peaks have been observed at different electrodes, which arise from the oxidation of thiocholine, which is the hydrolysis product of ATCl catalyzed by AChE. The oxidation peak current at e-GON-MWCNTs/GCE (curve c) is much higher and the peak potential shift negatively compared to those at GO-MWCNTs/GCE (curve b) and bare GCE (curve a). The phenomena can be attributed to the uniform loading of enzymes on the increased surface area and the excellent conductive properties, more electron transfer pathway provided by 3D e-GON-MWCNTs nanocomposite film. ${ }^{12}$

As shown in Fig. 4B, the peak currents on the e-GONMWCNTs/GCE increase linearly with the increase of scan rates from 10 to $200 \mathrm{mV} \mathrm{s}^{-1}$ (inset in Fig. 4B), indicating a typical surface-controlled electrode process. ${ }^{36}$

\subsection{Optimization parameters of the biosensor performance}

The relationship between the peak current and the $\mathrm{pH}$ of the electrolytes is shown in Fig. 5A. The maximum value appears at $\mathrm{pH}$ 7.4. Thus, the subsequent experiments carried out in $\mathrm{pH} 7.4$ solution. The effect of the loading amount of GO-MWCNTs on the biosensor response is also studied. The amperometric responses can improve significantly with increasing of GOMWCNTs up to $6.0 \mu \mathrm{L}$ (see Fig. 5B), indicating the 3D networks has formed on the electrode surface and they are of great benefit to sensitivity, after that, it decreases, because of increased resistance. ${ }^{20}$ Therefore, $6.0 \mu \mathrm{L}$ of GO-MWCNTs is used in further experiments.

Fig. 4 (A) DPV responses of (a) AChE/GCE, (b) AChE/GO-MWCNTs/GCE, (c) AChE/e-GON-MWCNTs/GCE in PBS containing 7.5 mmol L ${ }^{-1}$ ATCl. (B) CV curves of AChE/e-GON-MWCNTs/GCE in $0.1 \mathrm{M}$ PBS containing $7.5 \mathrm{mmol} \mathrm{L}^{-1} \mathrm{ATCl}$ at different scan rates from 10 to $200 \mathrm{mV} \mathrm{s}^{-1}$. Inset: the plots of peak current versus scan rate. 

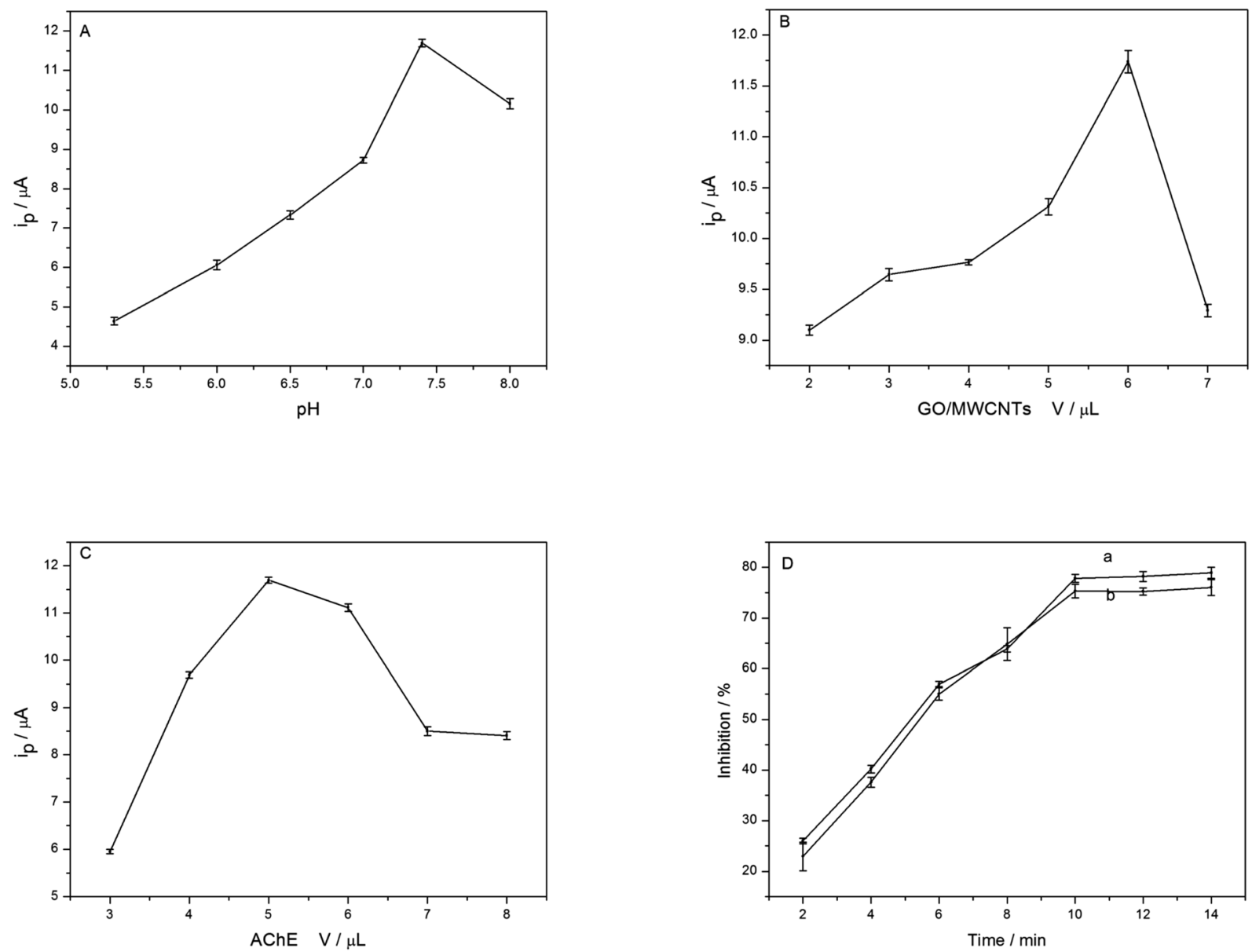

Fig. 5 Influence of the $\mathrm{pH}(\mathrm{A})$, the volume of GO/MWCNTs (B) and the amount of immobilized AChE (C) on the amperometric responses; the effect of the incubation time on inhibition efficiency (D), (a) carbofuran, (b) paraoxon.

The amount of AChE is also an important factor affecting the response of biosensor. With the increase of AChE volume, the current increase obviously and reach a maximum at $5.0 \mu \mathrm{L}$, and then decrease when the volume is increased further (Fig. 5C). It can be explained that the excessive thickness of AChE can possibly increase electrode resistance due to their poor electrical conductivity. Thus, $5.0 \mu \mathrm{L}$ of $\mathrm{AChE}$ is selected as the optimum amount for the biosensor. The effect of inhibition time is investigated with carbofuran (curve a in Fig. 5D) and paraoxon (curve b in Fig. 5D), respectively. The results show an increasing inhibition to AChE with the increase of inhibition time. When the incubation time exceeds $10 \mathrm{~min}$, the inhibitions do not change obviously and the maximum value is not $100 \%$, indicating reaching a saturation and equilibrium state. Therefore, $10 \mathrm{~min}$ is selected as incubation time.

\subsection{Calibration plot of ATCl}

The current-time curve of the AChE/e-GON-MWCNTs/GCE at $0.6 \mathrm{~V}$ with successive addition of ATCl into PBS buffer solution under stirring are shown in Fig. 6. With ladder increase of ATCl concentration, the oxidation current ladder grows. When the concentration of ATCl is saturated, the amperometric responses gradually tend to a plateau value. The inset (B) of Fig. 6 has shown the linear relationship between $i_{\mathrm{s}}^{-1}$ and $C^{-1}$ in the range of $4.7-9.2 \mathrm{mmol} \mathrm{L}^{-1}$. To value the enzymatic affinity, $K_{\mathrm{m}}$ is calculated according to the Lineweaver-Burk equation. $K_{\mathrm{m}}$ value

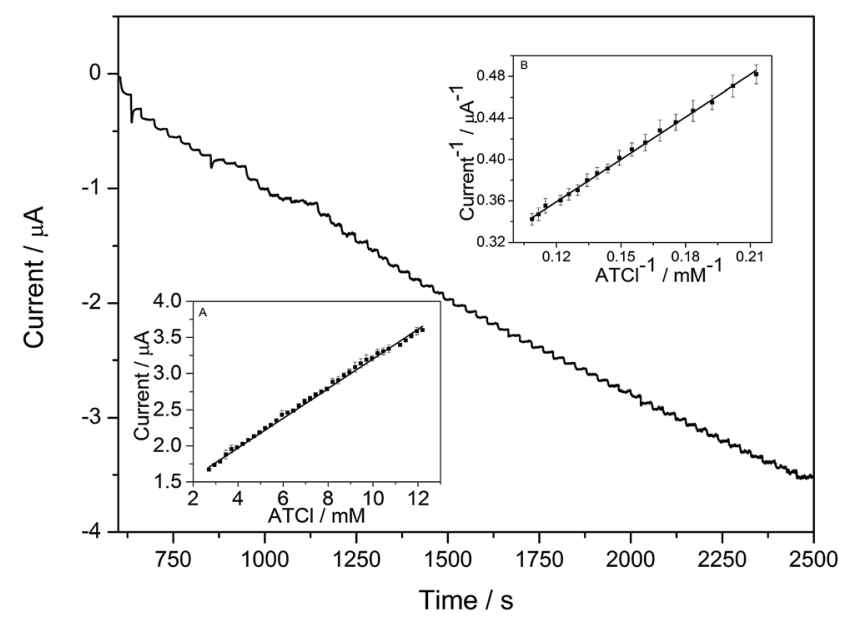

Fig. 6 The i-t curve of AChE/e-GON-MWCNTs/GCE electrode at $600 \mathrm{mV}$ with successive addition of different concentrations of $\mathrm{ATCl}$ into $0.1 \mathrm{~mol} \mathrm{~L}^{-1}$ PBS. Inset: the Lineweaver-Burk plot of $1 / i_{s} v s .1 / C$. 

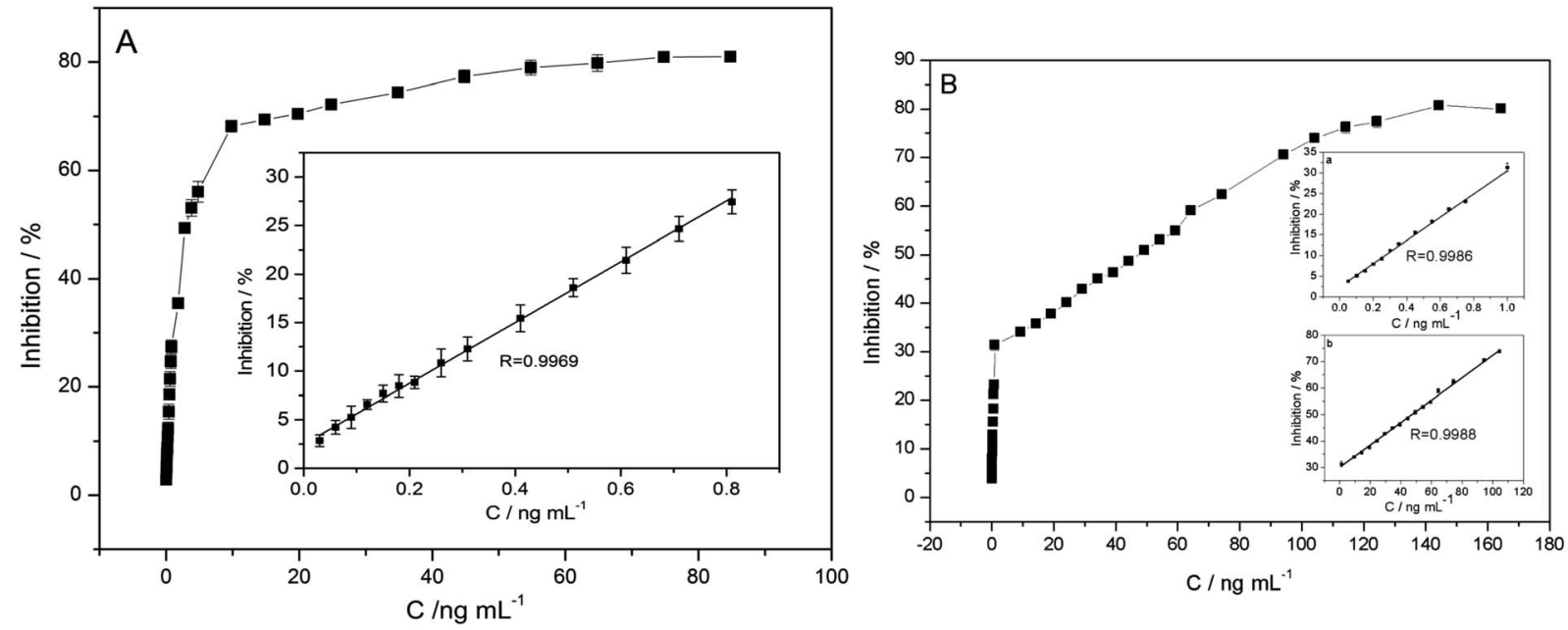

Fig. 7 The plots of the relationship between inhibitions and concentrations of carbofuran (A) and paraoxon (B). Inset: linear relationship between inhibitions and concentrations.

is $0.43 \mathrm{mmol} \mathrm{L}^{-1}$, which is obviously lower than $0.73 \mathrm{mmol} \mathrm{L}^{-1},{ }^{12}$ $0.7 \mathrm{mmol} \mathrm{L}^{-1} 19$ and $0.45 \mathrm{mmol} \mathrm{L}^{-1}{ }^{13}$ reported by literatures, suggesting the immobilized AChE displays a greater affinity to ATCl.

\subsection{Detection of carbofuran and paraoxon in standard solution}

Under the optimized variables, inhibition measurements are performed (Fig. 7). The inhibition of carbofuran is proportional to its concentration between 0.03 and $0.81 \mathrm{ng} \mathrm{mL}{ }^{-1}$, with the correlation coefficients of 0.9969 (Fig. 7A). Similarly, for paraoxon, the linear range is $0.05-1 \mathrm{ng} \mathrm{mL}^{-1}$ and $1-104 \mathrm{ng} \mathrm{mL} \mathrm{mL}^{-1}$, with the coefficients of 0.9986 and 0.9988 , respectively (Fig. 7B). The detection limits of carbofuran and paraoxon are $0.015 \mathrm{ng} \mathrm{mL} \mathrm{m}^{-1}$ and $0.025 \mathrm{ng} \mathrm{mL} \mathrm{m}^{-1}$, respectively. The results summarized in Table 2 have displayed that the biosensor herein have exhibited lower detection limit than the most of previous studies.

\subsection{Interference study}

The effect of the most common electroactive interfering substances has been studied. The comparisons of the signal for a $7.5 \mathrm{mmol} \mathrm{L}^{-1}$ of ATCl in the absence and presence of the interfering species are shown in Fig. S1. $\dagger$ The test results reveal that no obvious changes in current responses are found in the presence of $0.5 \mathrm{mmol} \mathrm{L}^{-1}$ glucose and $0.5 \mathrm{mmol} \mathrm{L}^{-1}$ oxalic acid, respectively. However, $9 \mathrm{nmol} \mathrm{L}{ }^{-1} p$-nitrophenol, $9 \mathrm{nmol} \mathrm{L}^{-1}$ $p$-toluenesulfonic acid, $9 \mathrm{nmol} \mathrm{L}^{-1}$ nitrobenzene and $1.8 \mathrm{nmol} \mathrm{L}^{-1}$ carbaryl slightly interfere the determination. Besides, equal concentration of paraoxon and carbofuran slightly interferes with each other for the detection.

\subsection{Repeatability and stability of biosensor}

The repeatability and stability of the proposed biosensor are evaluated. The same electrode is determined for 5 measurements, and the relative standard deviation (RSD) is calculated as $4.12 \%$ and $3.35 \%$ for carbofuran and paraoxon, respectively.

Table 2 Comparisons of the proposed AChE biosensor for the carbofuran and paraoxon with the contemporary AChE biosensors

\begin{tabular}{|c|c|c|c|c|}
\hline \multirow[t]{4}{*}{ Carbofuran } & AChE/PAMAMb-Au/CNTs/GCE & $1.06-19.91$ & 0.89 & 37 \\
\hline & $\mathrm{NF} / \mathrm{AChE}-\mathrm{CS} / \mathrm{SnO}_{2} \mathrm{NPs}-\mathrm{CGR}-\mathrm{NF} / \mathrm{GCE}$ & $2.21 \times 10^{-4}$ to $2.21 \times 10^{-2}, 2.21 \times 10^{-2}$ to 2.21 & $1.11 \times 10^{-4}$ & 39 \\
\hline & $\mathrm{AChE} / \mathrm{Fe}_{3} \mathrm{O}_{4}-\mathrm{CH} / \mathrm{GCE}$ & $1.11-19.91$ & 0.80 & 40 \\
\hline & PPy-AChE-Geltn-Glut/Pt & $0.025-2,5-60$ & 0.12 & 41 \\
\hline & AChE/ZnO-MWCNTs-sG/GCE & $0.275-7.156$ & $2.752 \times 10^{-4}$ & 43 \\
\hline & AChE/SWCNT-Co phtalocyanine/GCE & $5-50$ & 3 & 44 \\
\hline & PPy-AChE-Geltn-Glut/Pt & $0.1-12.5,12.5-150$ & 1.1 & 41 \\
\hline & $\mathrm{AChE} / \mathrm{Au}-\mathrm{MWNTs} / \mathrm{GCE}$ & $0.028-1.927$ & 0.028 & 45 \\
\hline & AChE/e-GON-MWCNTs/GCE & $0.05-1,1-104$ & 0.025 & This work \\
\hline
\end{tabular}


Table 3 Recovery studies of carbofuran and paraoxon in real samples

\begin{tabular}{|c|c|c|c|c|c|c|c|c|}
\hline \multirow[b]{2}{*}{ Sample } & \multicolumn{2}{|c|}{ Spiked (ng mL ${ }^{-1}$ ) } & \multicolumn{2}{|c|}{ Found (ng $\mathrm{mL}^{-1}$ ) } & \multicolumn{2}{|c|}{$\operatorname{RSD}(\%)(n=4)$} & \multicolumn{2}{|l|}{ Recovery (\%) } \\
\hline & Carbofuran & Paraoxon & Carbofuran & Paraoxon & Carbofuran & Paraoxon & Carbofuran & Paraoxon \\
\hline Spinach & 0.5 & 0.6 & 0.47 & 0.59 & 2.62 & 2.47 & 94.00 & 98.33 \\
\hline Cabbage & 20.0 & 19.3 & 19.75 & 18.99 & 1.96 & 2.14 & 98.75 & 98.39 \\
\hline Water & 54.0 & 74.0 & 55.29 & 74.81 & 2.05 & 2.31 & 102.38 & 101.09 \\
\hline
\end{tabular}

When stored in $0.1 \mathrm{M}$ PBS of $\mathrm{pH} 7.4$ at $4{ }^{\circ} \mathrm{C}$, it is found that the biosensor still retain $87 \%$ of its initial response to 20 days. The overall performance indicates that the biosensor shows good repeatability and stability.

\subsection{Real sample analysis}

To investigate the applicability of the fabricated biosensor, real samples are fortified with different amounts of pesticides. As shown in Table 3, the recoveries are found to be between $94.00 \%$ and $102.38 \%$, indicating that the biosensor is a useful analytical tool for carbofuran and paraoxon determination.

\section{Conclusions}

Combining the advantageous characteristics of the graphene and MWCNTs, the e-GON-MWCNTs nanocomposites have been synthesized by a facile and green strategy for immobilizing AChE for the determination of carbofuran and paraoxon. The eGON-MWCNTs nanocomposites facilitate the electron transfer and exhibit a high electrocatalytic activity to AChE, which can be attributed to the synergy effect of graphene and MWCNTs. The biosensor exhibits high sensitivity, low detection limit, longterm stability and good reproducibility. Moreover, it is promising for direct pesticides analysis in practical samples.

\section{Conflicts of interest}

There are no conflicts of interest to declare.

\section{Acknowledgements}

The authors thank the National Natural Science Foundation of China (21407100, 21574076, U1510121, 61504076 and 21501113) and the Natural Science Foundation of Shanxi Province (2014011016-1), the Program for the Top Young and Scientific and Technological Innovation Programs of Higher Education Institutions in Shanxi (02035290 1014).

\section{References}

1 A. Amine, H. Mohammadi, I. Bourais and G. Palleschi, Biosens. Bioelectron., 2006, 21, 1405-1423.

2 F. C. Moraes, L. H. Mascaro, S. A. Machado and C. M. Brett, Talanta, 2009, 79, 1406-1411.

3 R. Xue, T. F. Kang, L. P. Lu and S. Y. Cheng, Appl. Surf. Sci., 2012, 258, 6040-6045.
4 R. A. Videira, M. C. Antunes-Madeira, V. I. C. F. Lopes and V. M. C. Madeira, Biochim. Biophys. Acta, Biomembr., 2001, 1511, 360-368.

5 M. Asensio-Ramos, J. Hernández-Borges, L. M. Ravelo-Pérez and M. A. Rodríguez-Delgado, Anal. Bioanal. Chem., 2010, 396, 2307-2319.

6 A. Cappiello, G. Famiglini, P. Palma and F. Mangani, Anal. Chem., 2002, 74, 3547-3554.

7 Q. M. Zhang, L. S. Zhu, C. Han, J. Wang, H. Xie, J. H. Wang and S. J. Sun, J. Food, Agric. Environ., 2011, 9, 659-662.

8 J. W. Wong, M. K. Hennessy, D. G. Hayward, A. J. Krynitsky, I. Cassais and F. J. Schenck, J. Agric. Food Chem., 2007, 55, 1117-1128.

9 A. Crew, D. Lonsdale, N. Byrd, R. Pittson and J. P. Hart, Biosens. Bioelectron., 2011, 26, 2847-2851.

10 D. Du, M. Wang, J. Cai and A. Zhang, Sens. Actuators, B, 2010, 146, 337-341.

11 D. Du, X. Ye, J. Cai, J. Liu and A. Zhang, Biosens. Bioelectron., 2010, 25, 2503-2508.

12 Y. P. Li, Y. F. Bai, G. Y. Han and M. Y. Li, Sens. Actuators, B, 2013, 185, 706-712.

13 Y. P. Li, L. Y. Shi, G. Y. Han, Y. M. Xiao and W. Zhou, Sens. Actuators, B, 2017, 238, 945-953.

14 P. Raghu, B. E. Kumara Swamy, T. Madhusudana Reddy, B. N. Chandrashekar and K. Reddaiah, Bioelectrochemistry, 2012, 83, 19-24.

15 X. Sun and X. Wang, Biosens. Bioelectron., 2010, 25, 26112614.

16 D. D. Tuoro, M. Pottaccio, M. Lepore, F. Arduini, D. Miscone, U. Bencivenga and D. G. Mita, New Biotechnol., 2011, 29, 32138.

17 K. Wang, H. N. Li, J. Wu, C. Ju, J. J. Yan, Q. Liu and B. Qiu, Analyst, 2011, 136, 3349-3354.

18 Y. Wang, S. Zhang, D. Du, Y. Shao, Z. Li, J. Wang, M. H. Engelhard, J. Li and Y. Lin, J. Mater. Chem., 2011, 21, 5319-5325.

19 S. Wu, F. Huang, X. Lan, X. Wang, J. Wang and C. Meng, Sens. Actuators, B, 2013, 177, 724-729.

20 L. Yang, G. Wang and Y. Liu, Anal. Biochem., 2013, 437, 144149.

21 Y. Yang, A. M. Asiri, D. Du and Y. Lin, Analyst, 2014, 139, 3055-3060.

22 A. Ambrosi, C. K. Chua, A. Bonanni and M. Pumera, Chem. Rev., 2014, 114, 7150-7188.

23 M. F. L. De Volder, S. H. Tawfick, R. H. Baughman and A. J. Hart, Science, 2013, 339, 535-539. 
24 S. Kumar, W. Ahlawat, R. Kumar and N. Dilbaghi, Biosens. Bioelectron., 2015, 70, 498-503.

25 Q. Zhang, J. Q. Huang, W. Z. Qian, Y. Y. Zhang and F. Wei, Small, 2013, 9, 1237-1265.

26 N. Jung, S. Kwon, D. Lee, D. M. Yoon, Y. Min Park, A. Benayad, J. Y. Choi and J. Se Park, Adv. Mater., 2013, 25, 6854-6858.

27 P. Chen, T. Y. Xiao, Y. H. Qian, S. S. Li and S. H. Yu, Adv. Mater., 2013, 25, 3192-3196.

28 X. C. Dong, Y. W. Ma, G. Y. Zhu, Y. X. Huang, J. Wang, M. B. Chan-Park, L. H. Wang, W. Huang and P. Chen, J. Mater. Chem., 2012, 22, 17044-17048.

29 L. Daneshvar, G. Rounaghi, Z. E'shaghi, M. Chamsaz and S. Tarahomi, J. Mol. Liq., 2016, 215, 316-322.

30 A. A. Abdelwahab, Electroanalysis, 2016, 28, 1-7.

31 Q. Liu, A. R. Fei, J. Huan, H. P. Mao and K. Wang, J. Electroanal. Chem., 2015, 740, 8-13.

32 X. L. Qiu, L. M. Lu, J. Leng, Y. F. Yu, W. M. Wang, M. Jiang and L. Bai, Food Chem., 2016, 190, 889-895.

33 C. L. Sun, C. T. Chang, H. H. Lee, J. Zhou, J. Wang, T. K. Sham and W. F. Pong, ACS Nano, 2011, 5, 7788-7795.
34 Y. Z. Chang, G. Y. Han, M. Y. Li and F. Gao, Carbon, 2011, 49, 5158-5165.

35 E. Katz and I. Willner, Electroanalysis, 2003, 15, 913-947.

36 D. Du, J. W. Ding, J. Cai and A. D. Zhang, J. Electroanal. Chem., 2007, 605, 53-60.

37 Y. H. Qu, Q. Sun, F. Xiao, G. Y. Shi and L. T. Jin, Bioelectrochemistry, 2010, 77, 139-144.

38 C. Zhai, X. Sun, W. P. Zhao, Z. L. Gong and X. Y. Wang, Biosens. Bioelectron., 2013, 42, 124-130.

39 Q. Zhou, L. Yang, G. C. Wang and Y. Yang, Biosens. Bioelectron., 2013, 49, 25-31.

40 T. Jeyapragasam and R. Saraswathi, Sens. Actuators, B, 2014, 191, 681-687.

41 R. Dutta and P. Puzari, Biosens. Bioelectron., 2014, 52, 166172.

42 G. X. Yu, W. X. Wu, Q. Zhao, X. Y. Wei and Q. Lu, Biosens. Bioelectron., 2015, 68, 288-294.

43 P. Nayak, B. Anbarasan and S. Ramaprabhu, J. Phys. Chem. C, 2013, 117, 13202-13209.

44 A. Ivanov, R. Younusov, G. Evtugyn, F. Arduini, D. Moscone and G. Palleschi, Talanta, 2011, 85, 216-221.

45 N. Jha and S. Ramaprabhu, Nanoscale, 2010, 2, 806-810. 